\title{
Projecting the demographic impact of Syrian migration in a rapidly ageing society, Germany
}

\author{
Niall Newsham ${ }^{1} \cdot$ Francisco Rowe $^{1}$ (D) \\ Received: 15 December 2017 / Accepted: 27 December 2018 / Published online: 22 January 2019 \\ (c) The Author(s) 2019
}

\begin{abstract}
Trends of persistent low fertility and increasing life expectancy have set Germany to undergo rapid population ageing and decline. In the context of the Syrian refugee crisis, immigration has been considered as a key mechanism to combat these demographic outlooks. This study assesses the demographic impact of Syrian migration into Germany. Deterministic and Bayesian probabilistic projection methods are used to determine the contribution of Syrian migrants to aggregate total fertility rate and the likelihood of subsequent population growth. Findings reveal that Syrian migration is projected to increase German period total fertility but not by the required levels to prevent depopulation. Whilst Syrian migration into Germany has been substantial over the past few years, fertile female cohorts are largely underrepresented in the migrant population and so only a moderate net-effect of Syrian migrants on German fertility is forecasted. A solution to Germany' population decline may thus not be offered through Syrian migration, with depopulation projected to be a likely scenario.
\end{abstract}

Keywords Refugee migration · Demographic impacts · Bayesian probabilistic projections $\cdot$ Germany $\cdot$ Population decline $\cdot$ Population ageing

JEL classification $\mathrm{C} 53 \cdot \mathrm{J} 11 \cdot \mathrm{F} 22 \cdot \mathrm{O} 52$

Francisco Rowe

F.Rowe-Gonzalez@liverpool.ac.uk

Niall Newsham

Niallnewsham22@gmail.com

1 Geographic Data Science Lab, Department of Geography and Planning, University

of Liverpool, Liverpool, UK 


\section{Introduction}

European populations are beginning to experience a previously not recorded change in human history. Population growth has been supressed since the second half of the twentieth century and set European countries for a trajectory of depopulation. Population decline has prevailed in post-soviet Eastern European states for almost three decades and is beginning to emerge in more populous and economically advanced Western European nations. Despite regional demographic differences, European population decline is expected to commence within the next 5 years, reducing the continental population by around 25 million, or $3 \%$, by 2050 (UN 2017). Population decline would impose major challenges on Europe, leading to declines in economic productivity and growth and increasing pressures on social welfare (Bloom et al. 2010; Coleman and Rowthorn 2011). Depopulation may potentially change the global geopolitical and economic structure, diminishing European nations.

European population decline is predominantly linked to below-replacement fertility (Bosch 2000; Coleman and Rowthorn 2011). Despite rises in life expectancy and net-migration gains, European fertility rates have long been insufficient to support population growth as low fertility has remained an inseparable feature of European demography for around 40 years (UNDP 2013). The depopulating effect of sub-replacement fertility has thus far been negated by a positive demographic momentum and migration inflows (Haug et al. 2002; Coleman and Rowthorn 2011). Considering the causal relationship between low-fertility rates and depopulation, an obvious solution would be to increase fertility outcomes. However, government incentives have been received with varying levels of success, and in some extreme instances, fertility has actually decreased due to incompatibilities between fertility initiatives and modern, labour committed family systems (Neyer and Andersson 2008; Thomas et al. 2019). An alternative solution may be offered through increased migration inflows (Alho et al. 2006; Coleman 2008). Positive net-migration is a known short-term solution to modern challenges imposed by low fertility, namely labour shortages (McDonald 2006). However, recently studies have examined the long-term demographic impacts of immigration, with a specific focus on consequential increases to fertility rates (Sobotka 2004, 2008; Goldstein et al. 2009). Empirical studies have reported total fertility increases due to an increasing share of births from immigrant women in various European countries including Norway, France, Spain, Italy and the UK (Østby 2002; Tromans et al. 2009). There is therefore a genuine potential for population decline to be averted through migration gains.

Immigration represents a unique opportunity to stimulate population growth and secure demographic stability in Europe, at least for the near future. Since 2011, just fewer than 1 million displaced migrants from Syria have applied for asylum in Europe (UNHCR 2017), although the number of actual arrivals into Europe is estimated to be greater (Quinn 2016). The decision regarding the accommodation of Syrian migrants has been a polarising political issue, as represented by the unequal distribution of Syrian migrants across Europe. Of all 
European nations, Germany has accommodated the most migrants, most recently estimated at 507,795 or 52.3\% (UNHCR 2017). As a nation likely facing depopulation in the near future (UN 2017), the arrival of such a vast migrant population presents an opportunity to combat such demographic challenges in both the short term and long term, if increases to aggregate fertility are a consequence.

Whilst there exists some literature concerning aggregate fertility increases through immigration, improvements from forced migration events are yet to be examined. This study aims to address this gap through examining the demographic response to recent Syrian migration in a low-fertility setting, Germany, primarily through assessing the extent of aggregate fertility contributions from migrants and subsequent population change. Particularly, we seek to quantify the potential changes in size and age structure of the German population and determine their regional variations across German states. We draw on demographic data from the German federal statistics office and Syrian asylum migrant applications from the United Nations High Commissioner for Refugees (UNHCR) for the 2011-15 period. By applying traditional cohort component methods, we estimate fertility responses. We also examine the long-term impact of Syrian migration on the future population of Germany by applying Bayesian probabilistic projection models to produce population projections up to 2100 . These long-term projections will enable an assessment of the likelihood of population trajectories under expected future fertility and mortality levels.

\section{Background}

\subsection{Demographic change}

European countries have long been considered the forerunners of demographic change. As after all, the foundations of demographic transition theories were based upon empirical regularities across Europe or in nations with large European immigrant populations (Kirk 1996). It is generally accepted that Europe has completed the conventional Demographic Transition Model and is now entering a new period characterised by unfamiliar demographic traits, notably further reductions in fertility well below the level of replacement at around 2.1 births per woman. This era of modern demographic change is subject to numerous, often complimentary, theories that seek to provide an explanation. Many of which allude to the liberalisation of societal attitudes towards marriage and living arrangements (Van de Kaa 2002), gender equity in domestic and institutional settings (McDonald 2000) and a greater individual autonomy in regard to one's life choices (Beck and Beck-Gernsheim 2002).

Arguably the most important event in recent demographic change is fertility postponement. This refers to the occurrence of childbearing at increasingly later stages of one's fertile period. Postponement has become a common feature of modern European fertility regimes and is often cited as the most significant determinant of low fertility in Europe (Kohler et al. 2002; Billari 2008, Goldstein et al. 2009; Sobotka 2017; Thomas et al. 2019). The primary impact of postponement on fertility is the 
distortion of period rates. In other words, total fertility is temporarily reduced due to tempo effects associated with the delay of childbearing (Bongaarts and Feeney 1998). However, this ultimately decreases total fertility as only a partial recuperation of pre-postponement fertility is attained (Lesthaeghe and Willems 1999). This is because fertility postponement is negatively associated with the quantum of fertility, defined as the would-be observed total fertility rate (TFR) in the absence of tempo effects, largely through irreversible increases in educational and labour force gender equity which influence both fertility postponement and quantum (Kohler et al. 2002). An increase and subsequent stabilisation of fertility can be expected once the postponement transition is complete (Bongaarts and Sobotka 2012), although it is likely that this will be lower than replacement level due to quantum reductions (Sobotka 2017). This essentially means that natural population decline is imminent, regardless of anticipated total fertility recuperation.

Low fertility has persisted throughout Europe since its inception (UN 2017). Its effects on overall population structure and size have been gradual but significant. Two demographic phenomena are attributed to low fertility, population ageing and natural decline (Lutz et al. 2003; Coleman and Rowthorn 2011). Below-replacement fertility in any society, even one that has considerable positive net-migration flows, will produce an ageing population. The pace of population ageing is determined by the extremities of low fertility and mortality outcomes, both of which are generally characteristics of European countries. Secondly, depopulation can occur after a sustained period of below-replacement fertility. In theory, natural decline can occur at any time since it is simply a result of a birth deficit. However, demographic momentum, supported by increasing longevity and moderate low fertility, can sustain population growth whilst experiencing such a deficit. For this reason, depopulation is not currently widespread across Europe, but an equal number of countries are experiencing natural population growth and decline (Table 1). In a comparison with a similar investigation by Coleman and Rowthorn (2011), a greater number of countries are currently experiencing natural depopulation than in 2008, suggesting that the demographic mechanisms that produce a decline are becoming more widespread.

Even when considering the expected recuperation of European fertility following the end of the postponement transition, recent population projections display declines for total European population by the end of the century (UN 2017). Depopulation therefore appears imminent for Europe, bringing with it a whole host of economic and social challenges, namely a decline in economic productivity and therefore growth (Bloom and Sousa-Poza 2010; Coleman and Rowthorn 2011), in addition to issues relating to welfare and healthcare provision as a direct consequence of the inseparable population ageing phenomenon (Bloom et al. 2010; Bloom 2011) and changing trends of internal migration rates (Rowe 2018).

Whilst the consequences of decline are well known and therefore foretold, solutions are relatively sparse. Most deliberate attempts to combat modern demographic challenges involve the promotion of fertility, predominantly in the form of governmental initiatives and incentives. Newly introduced policies across Europe have been met with various levels of success (Neyer and Andersson 2008). German fertility policies are orientated towards the traditional male breadwinner family system and have failed to recognise modern social developments, namely increased 
Table 1 Population change across Europe, 2016 (per 1000 population). Source: Eurostat Dataset available: http://ec.europa.eu/eurostat/web/products-datasets/-/tps00019

\begin{tabular}{|c|c|c|c|c|c|c|c|}
\hline \multicolumn{4}{|l|}{ Natural change } & \multicolumn{4}{|l|}{ Absolute change } \\
\hline \multicolumn{2}{|c|}{ Increasing populations } & \multicolumn{2}{|c|}{$\begin{array}{l}\text { Decreasing popula- } \\
\text { tions }\end{array}$} & \multicolumn{2}{|c|}{ Increasing populations } & \multicolumn{2}{|c|}{$\begin{array}{l}\text { Decreasing popula- } \\
\text { tions }\end{array}$} \\
\hline Ireland & 7.1 & Bulgaria & -6 & Luxembourg & 19.8 & Lithuania & -14.2 \\
\hline Iceland & 5.1 & Serbia & -5.1 & Iceland & 17.4 & Latvia & -9.6 \\
\hline Albania $^{\mathrm{a}}$ & 3.6 & Ukraine $^{\mathrm{a}}$ & -4.3 & Sweden & 14.5 & Croatia & -8.7 \\
\hline Luxembourg & 3.6 & Lithuania & -3.7 & Malta & 13.8 & Bulgaria & -7.3 \\
\hline Norway & 3.5 & Romania & -3.5 & Switzerland & 10.8 & Romania & -6.2 \\
\hline France & 3 & Croatia & -3.4 & Ireland & 10.6 & Serbia & -5.1 \\
\hline United Kingdom & 2.7 & Latvia & -3.4 & Austria & 9.5 & Hungary & -3.4 \\
\hline Switzerland & 2.7 & Hungary & -3.2 & Norway & 8.5 & Portugal & -3.1 \\
\hline Sweden & 2.7 & Greece & -2.4 & Germany & 7.6 & Ukraine $^{\mathrm{a}}$ & -2.8 \\
\hline Malta & 2.6 & Portugal & -2.3 & Denmark & 7.2 & Greece & -2.5 \\
\hline Montenegro & 1.8 & Italy & -2.3 & United Kingdom & 6.5 & Albania $^{\mathrm{a}}$ & -2.2 \\
\hline Denmark & 1.5 & $\begin{array}{l}\text { Bosnia \& } \\
\text { Herzego- } \\
\text { vina }\end{array}$ & -1.8 & Netherlands & 6 & $\begin{array}{l}\text { Bosnia \& } \\
\text { Herzego- } \\
\text { vina }\end{array}$ & -1.8 \\
\hline Netherlands & 1.4 & Germany & -1.8 & Belgium & 4.8 & Italy & -1.3 \\
\hline Belgium & 1.2 & Estonia & -1 & France & 4 & Moldova $^{\mathrm{a}}$ & -0.6 \\
\hline Macedonia & 1.2 & Russia $^{a}$ & -0.9 & Finland & 2.9 & Estonia & -0.2 \\
\hline Slovakia & 1 & Moldova $^{a}$ & -0.4 & Czech Republic & 2.4 & & \\
\hline Austria & 0.8 & Finland & -0.2 & Spain & 1.9 & & \\
\hline Czech Republic & 0.5 & Poland & -0.2 & Slovakia & 1.7 & & \\
\hline \multirow[t]{6}{*}{ Slovenia } & 0.3 & Belarus & -0.2 & Russia $^{a}$ & 1.4 & & \\
\hline & & & & Macedonia & 1.2 & & \\
\hline & & & & Slovenia & 0.8 & & \\
\hline & & & & Belarus & 0.7 & & \\
\hline & & & & Montenegro & 0.3 & & \\
\hline & & & & Poland & 0.2 & & \\
\hline
\end{tabular}

UN European countries included only. Spain reported stable population

${ }^{a}$ Indicates older data than 2016, Russia collected in 2011, all others 2015

female labour force participation (ibid:703). German policies have therefore been unsuccessful due to incompatibilities between employment and childrearing incentives (Prskawetz et al. 2006). An alternative solution may lie with the promotion of positive net-migration (Alho et al. 2006). Migration influxes immediately add to total population size and thus promote growth. When considering absolute population change, including net-migration, only 15 European countries (38.5\%) remain in decline compared with the $19(48.7 \%)$ in natural decline (Table 1). It would then appear that several countries are successfully combatting depopulation through migration influxes. However, this solution should only be perceived as temporary unless considerable improvements to fertility are a consequence, since migration 
would simply postpone depopulation. Increases in fertility have previously been reported in Europe as a consequence of migration (see Sobotka 2008) and so this is not completely beyond the realms of possibility. In considering the two-dimensional benefits, migration represents a medium through which both short- and long-term demographic challenges can be alleviated.

Of all European countries, few are more suited than Germany to be subject of a study into the demographic consequences of mass migration. Firstly, despite postwar economic disruptions, Germany has experienced the same demographic trends as the rest of Europe, notably increased longevity, the baby boom phenomenon and subsequent fertility decline. Rather than conforming to the latter, Germany can be perceived as forerunner of low fertility, having experienced declines earlier and with greater intensity than other European nations (Sobotka 2011). Secondly, low fertility has persisted for almost half a century despite government-led family planning initiatives (Prskawetz et al. 2006). As a consequence, a natural population decline can be observed (Coleman and Rowthorn 2011, Table 1). Thirdly, Germany has a long history of in-migration, with considerable inflows characteristic of post-war and reunification Germany, in particular (DESTATIS 2017a). Immigration has been integral to population growth, actually compensating for a natural decline since 1970 (Haug et al. 2002, Table 1). Germany therefore has an established migrant background, and one which has already impacted on the size and structure of its population (Mammey and Schwarz 2002). Finally, and perhaps most importantly, Germany has received over 500,000 first time asylum applications from Syrian since the start of political disruption in 2011 (UNHCR 2017). This represents a considerable influx of migrants that possess different demographic characteristics than the native population. Considering stagnant fertility levels and the consequential threat of depopulation in Germany, Syrian migration presents a unique opportunity to examine the demographic consequences of mass migration into a developed nation in need of a stimulus to population growth.

\subsection{Migrant fertility}

In recent times, Europe has experienced considerable immigration inflows, drastically altering its demographic landscape (Coleman 2006). The majority of related literature has focused on the immediate demographic impact of immigration, namely the direct modification of population size and composition. However, migration has been found to also influence aggregate fertility outcomes through increased completed births resulting from an enlarged fertile cohort (Goldstein et al. 2009). This is routinely overlooked in academic studies despite the potential for the alleviation of prospective demographic challenges, including population decline.

Since fertility preferences and outcomes are dependent on socio-economic, cultural and environmental mechanisms (Bongaarts 1978), variation over space is an inherent quality. It is then expected that international migrants will possess different demographic traits to native populations, particularly when distance between origin and destination is greater. Typically in the context of European immigration, migrants tend to exhibit higher period and parity-specific fertility rates than 
the average native woman (Sobotka 2008; Kulu et al. 2017). TFR differentials of 0.3-0.8 are typically reported (Sobotka 2008; Goldstein et al. 2009), although differences greater than 1 are not uncommon (Héran and Pison 2007). Thus in instances of substantial migration influxes, fertility rates have increased as a result of an increased share of births to non-native women (Østby 2002; Tromans et al. 2009). Although the extent of such increase is country-specific, the net impact of migration on total fertility typically ranges between 0.05 and 0.1 (Sobotka 2008). Whilst this may appear small, the opportunity for a fertility boost through the promotion of positive net-migration should be welcomed by nations with low fertility.

The contribution to aggregate fertility levels from migrants has been gradually increasing across Europe (Sobotka 2008). No more is this true than in Germany, where births to mothers with foreign citizenship have risen steadily, and now account for one fifth, or 20.1\%, of total live births (DESTATIS 2017b). In respects to fertility differences between immigrant and native populations in Germany, studies have found that total fertility and parity-specific fertility is greater amongst firstgeneration migrants (Kulu et al. 2017; Milewski 2010) but less than in respective countries of origin (Mammey and Schwarz 2002). It is difficult to assess whether the fertility outcomes of Syrian migrants will resemble that of previous immigrants into Germany. Fertility outcomes of Turkish migrants are predominantly examined in empirical studies, and so moderate similarities could be somewhat expected given the close proximity of Turkey to Syria. However, the situations leading to migration are contrasting. Turkish migrants were voluntary, since they were recruited to combat labour force scarcities. In contrast, Syrian migrants were displaced due to internal conflicts and are considered as forced migrants. Therefore, Syrian migrants are more likely to be subject of disruptive influences that inhibit fertility.

\subsection{Forced migrant fertility}

Studies concerning forced migrant fertility generally adopt a temporal framework that describes the systematic disruption of fertility throughout the migration process. During the three phases of migration (flight, temporary residence and resettlement), different disruptive forces operate and have either a direct or indirect impact on fertility inhibition. These may be considered voluntary, such as deliberate postponement, or involuntary through spousal separation, for example. In order to generate assumptions of possible fertility outcomes of Syrian migrants, it is important to first consider potential repercussions of forced migration.

The initial phase incorporates everything from pre-flight to early settlement into a temporary camp. Here direct disruptions to fertility are most prevalent due to unsettlement and uncertainty. For example, Randall (2004) reports initial fertility disruptions to Tamasheq migrant populations due to famine complications. This represents a biological disruption which can also include disease, stress, a loss of libido, infant mortalities and amenorrhoea (ibid). Other potential factors include the presence of selection mechanisms prior to actual movement (see Agadjanian 2018), psychological-related disruptions and biosocial complications such as spousal separation (Randall 2004). Spousal separation is central to the disruption hypothesis (Goldstein 
1973) and is therefore likely to disrupt fertility outcomes at least until reunification (Agadjanian 2018). In Syrian migrant populations, family separation may persist for extended periods beyond this initial phase.

The second phase, or the period of limbo, sees displaced populations settle into temporary societies. This introduces indirect disruptions that operate in more stable societies such as socio-economic mechanisms. According to Ostrand (2015), the vast majority of Syrian migrants that moved to neighbouring countries (96\% 2011-2014 estimate) have settled in established settlements, not designated refugee camps. This has placed an immediate strain on essential services, resulting in migrants living in unsanitary conditions and under poverty. This would seemingly prolong and perhaps exaggerate disruption mechanisms of all types, including those characteristics of the flight phase. For those that reside within official refugee camps, both within the immediate region and in other continents, basic services are said to be provided (ibid:263), perhaps eradicating disruptions slightly. However, Dhesi et al. (2018) outline insufficiencies of such provisions in refugee camps in Calais, France, that have promoted poor health outcomes. Fertility is therefore not supported in these camps, and certainly deliberate postponement is plausible. Additionally, conditions in refugee camps will be subject to deterioration through overpopulation, perhaps further reducing fertility outcomes. Whilst monthly Syrian refugee applications to Europe are down from peak 2015 levels (UNHCR 2017), camp population is ultimately determined by succession into the final phase, resettlement.

The final resettlement phase is arguably most important for this study as the long-term demographic impact of forced migration is the primary focus. This phase concerns settlement into a host nation and subsequent integration into a new, established, society. Active fertility determinants in this stage bare resemblance to those of voluntary migration, with the extent of integration a considerable factor. Forced migrants in Europe will be presented with various socio-economic opportunities that are characteristic of economically developed societies. These include increased labour force and educational prospects as well as access to improved health and family planning resources. In a traditional, non-migratory, setting these would decrease fertility through increasing opportunity costs of childbearing and contraceptive use, respectively (Bongaarts 1978; Rindfuss and Brewster 1996). However, the significance of these fertility determinants will largely be dependent on the extent of integration. It is possible that socio-economic exclusion will be greater for forced migrants than that of voluntary migrants (Agadjanian 2018), particularly when migration to a culturally dissimilar place occurs. This would certainly hinder integration and promote the existence of minority sub-cultures and thus preserve high fertility norms.

Empirical studies, though few, find that immediate fertility declines in the early stages of the migration process are not sustained as fertility tends to recover to premigration levels in the final migration stages (Hill 2004; Randall 2004). However, forced migration events are unique in every aspect from the initial crises to temporary sanctuary to eventual resettlement. Individual experiences can also differ considerably throughout the process, making exposure to the various fertility deterrents highly personal. Therefore, the expectation of similar fertility outcomes for Syrian migrants cannot be accepted, at least at this early stage. In order to account for 
uncertainties in eventual fertility outcomes, this study will consider the demographic impact of Syrian migrants in Germany under a variety of plausible scenarios.

\subsection{Fertility in population forecasts}

Population projections are beneficial to numerous persons and organisations for policy, planning, marketing and research purposes, particularly when confronting a significant demographic event such as depopulation. However, their usefulness is entirely dependent on accuracy. As with any kind of prediction or projection, the presence of uncertainty is undeniable. This is particularly true for population projections as the sources of uncertainty are so vast (Lee 1998). Recent literature has aimed to reduce such uncertainty through the advancement of forecasting methodologies (Keilman et al. 2002; Booth 2006). There has been a clear shift towards the adoption of probabilistic methods over traditional deterministic techniques amongst academics, resulting in the publication of updated estimations (Raftery et al. 2012) and the adoption of such methods by the United Nations in biennial world population projection (WPP) publications (UN 2017).

All models must consider uncertainty in regards to fertility, mortality and migration outcomes, as subtle changes in either of these will largely influence the size and composition of future populations. Deterministic models account for this through the application of the scenario approach, in which high and low demographic possibilities are considered. This has been the subject of frequent criticism as it fails to explicitly detail the uncertainty of forecasts in probabilistic terms (Keilman et al. 2002; Raftery et al. 2012; Alkema et al. 2015). Put simply, deterministic methods do not provide any indication of the likelihood of the realisation of low or high variants. In contrast, probabilistic methods outline the probability of future population values (Wiśniowski et al. 2015). This should be considered as a considerable advantage, as uncertainty is inherent to population projections therefore its quantification ought to be included within forecasts.

Both deterministic and probabilistic projection models apply the cohort component method, or the Leslie matrix method (Leslie 1945). This is considered the standard approach to forecasting future populations. The method involves simple accounting techniques to project forward the size and age-sex distribution of fiveyear cohorts. Baseline demographic data, consisting of population size and structure, are accompanied by age-specific fertility, survival and net-migration data to estimate future populations in five-year sequences (Preston et al. 2001). The first projection (year $t+5$ ) is able to make use of existing data for these demographic variables. However, since fertility, mortality and migration outcomes are non-constant, subsequent projections must rely on assumptions based on either qualitative or quantitative judgement. The way in which such assumptions are generated is dependent on whether a deterministic or probabilistic model is applied.

Forecasting fertility is particularly difficult as both quantum and tempo outcomes are subject to influence from a range of direct and indirect determinants (Booth 2006). Fluctuation in TFR is therefore inherent, rendering fertility as largely unpredictable, particularly in long-term forecasts. In traditional deterministic models, 
uncertainties relating to future fertility outcomes are captured through the application of the scenario approach (UN 2001 chap. 5, ONS 2015, Federal Statistical Office Wiesbaden 2015). This has been criticised as it does not address uncertainties, rather just demonstrate the sensitivity of future population to broad fertility possibilities (Alkema et al. 2011). The emergence of wide-scale probabilistic projection use represents the addressing of this criticism. Currently the most advanced population projections employ Bayesian hierarchical models (BHM) to simulate future values of fertility. Developed by Alkema et al. (2011), the model considers both countryspecific demographic history and global commonalities to produce tailored forecasts for any nation. The methodology is based on the sequence of fertility decline, representing the progression through the demographic transition. Three phases of distinctive fertility sequences are outlined and modelled separately using unique methods, as different determinants are responsible for changes in each phase (Alkema et al. 2011). Stage one is the pre-transition phase, where TFR is stable at around 6 or 7. Stage two accounts for TFR reductions during the transition. Stage three, or the post-transition phase, considers the expected recovery of below-replacement fertility towards replacement level and subsequent fluctuations.

\section{Methodology}

The German federal statistics office, Statistisches Bundesamt, annually publishes demographic estimates concerning population composition, fertility, mortality and migration trends. Comprehensive demographic data on Syrian immigration, however, do not yet exist as it is still unfolding, with applications for asylum still being received. This study draws on demographic data for the 424,175 registered Syrian asylum applicants into Germany from year-beginning 2011 to year-end 2015. Most recent UNHCR (2017) figures estimate the total number of applicants into Germany (from year-beginning 2011 to mid-2017) to stand at 507,795. Therefore, the vast majority (83.54\%) of asylum applicants are considered in study.

Our analysis comprises two methodologies. The first involves the use of deterministic projections to quantify the demographic impacts of Syrian migration into Germany. A cohort component model is used to explore possible demographic outcomes according to various Syrian migrant fertility scenarios by forecasting fertility rates (ASFR and TFR) for year $t+5$. The second methodology involves the use of Bayesian probabilistic population projection models to examine long-term population changes resulting from the recent Syrian migration influx based on fertility rates estimated in the first stage of analysis. Bayesian projections provide more sophisticated estimations as they consider fluctuations in fertility, mortality and migration and assess probabilistically the likelihood of future demographic outcomes.

Before providing a more detailed description of our methods, it is first important to explain the required input data structure. Data on Syrian migrant counts were organised by five-year age and sex cohort for deterministic aggregate fertility projections. However, available data on the demographic composition of Syrian migrant populations are inconsistently aggregated across the UNHCR and Statistisches Bundesamt data sources. The UNHCR provides a breakdown of migrants by age and 
sex for all Syrian migrants, whilst Statistisches Bundesamt provides only the count of migrants in Germany. Neither of these sources explicitly detail the demographic breakdown of the migrant population for use in a cohort component model. To overcome this, the following procedure was applied:

a) Use German Migrationsbericht Syrian migrant count (2011-2015) and UNHCR proportion (\%) of irregular Syrian migrant cohorts (0-4, 5-11, 12-17, 18-59, $60+$ ) data to calculate the total count of each irregular UNHCR cohort.

b) Use a separate UN dataset consisting of regular five-year Syrian age and sex cohort count estimates $(0-4,5-9,10-14$, etc.) for disaggregation into single-year estimates, assuming an equal distribution within each five-year cohort (i.e. the count for females aged 3 is assumed to be identical to that for female aged 4).

c) Calculate the relative proportion (\%) of these single-year cohorts in respective irregular UNHCR cohorts (e.g. of the 5-11 cohort, $14.36 \%$ are aged 9).

d) Multiply these percentages by the counts of each irregular UNHCR cohort (from stage 1) to estimate the count of each single-year cohort by age and sex.

e) Sum these single-year counts to calculate the total count of Syrian migrants by regular five-year cohort and sex.

\subsection{Cohort component projections}

Using the cohort component method, five different TFR forecasts were produced representing possible fertility outcomes of the Syrian population in Germany. We used the cohort component method. It is the most common to produce deterministic population forecasts and involves projecting forwards a population at year $t$, divided into sex and five-year age cohorts, in 5-year periods by considering the impact of birth, death and net-migration rates. The method requires cohort fertility (ASFR), survivorship probabilities and net-migration data. ASFR data were collected from 2015 UN cohort fertility estimations for both German and Syrian women, whilst survivorship and net-migration data were acquired from the German Statistical Office. In total, there are three distinct phases for the cohort component methodology. The first stage involves the separate calculation of birth outcomes for native and Syrian populations using the following equation:

$$
B_{n}=E_{n} \cdot \mathrm{ASFR}_{n} \cdot 5
$$

where $B_{n}$ denotes the total birth count of a particular fertile cohort, $n ; E_{n}$ denotes the number of person-years of exposure in cohort $n$, between years $t$ and $t+5$; and, $\mathrm{ASFR}_{n}$ represents the age-specific fertility rate of cohort $n$. This is carried out for each of the seven childbearing cohorts (15-19, 20-24, 25-29, 30-34, 35-39, 40-44, and 45-49) for both native and Syrian women.

Rearranging (1), aggregate cohort fertility can be calculated as follows:

$$
a \mathrm{ASFR}=a B n / a E n
$$

where $a B_{n}$ denotes the aggregate number of births from a particular cohort (Syrian and German births combined); and, $\mathrm{a} E_{n}$ denotes the aggregate number of personyears of exposure in cohort $n$. 
Finally, the total period fertility of year $t+5$ is calculated using (3):

$$
a \mathrm{TFR}=\sum_{n}^{n+7} a \mathrm{ASFR}
$$

where $n$ represents the first reproductive cohort (ages 15-19) and $n+7$ represents the last (ages 44-49). Since fertility events are not confined to these ages, it is possible to include births from women outside of these cohorts. However due to the relative infrequency of such events, fertility outcomes have been found to be insignificant (Vanella 2016). For this reason, these are not considered here.

Various assumptions were made for cohort component models to suppress uncertainties relating to future fertility, mortality and migration trends. Table 2 reports the assumptions for the five scenarios considered. The assumptions remain constant for all cohort component models. The assumptions are:

- That survivorship ratios of German cohorts apply to migrant populations (both Syrian and non-Syrian) from year 1 . Thus, this study does not consider the likely differences in health status (Dhesi et al. 2018) or lifestyle preferences.

- That fertility rates at year $t+5$ remain constant throughout the projection horizon. Therefore, this study overlooks possible cohort fertility adjustments at the end of the postponement transition. This deficient is, however, overcome in our Bayesian projection models.

- That the sex ratio at birth remains constant throughout the projection period.

- That non-Syrian net-migration remains constant throughout the projection horizon. Of the components of population change, international migration is the most difficult to forecast (Coleman 2008:465). Following the standard practice in demographic forecasts (Booth 2006), migration is assumed to remain constant.

Table 2 Syrian migrant fertility scenarios for cohort component projection models

\begin{tabular}{lll}
\hline Scenario & TFR & Assumptions \\
\hline Highest & 3.101 & $\begin{array}{l}\text { Fertility remains at pre-migration levels throughout the simulation } \\
\text { No disruptions during migration process, however unlikely (Randall } \\
\text { 2004) }\end{array}$ \\
High & 2.682 & $\begin{array}{l}\text { Fertility levels are in-between that of highest and median scenario } \\
\text { Represents moderate level of integration in which sub-cultures are effec- } \\
\text { tive in preserving high fertility outcomes }\end{array}$ \\
Median & 2.264 & $\begin{array}{l}\text { Fertility is directly in-between that of highest and lowest scenarios } \\
\text { Considers equal influence of sub-culture preservation and integration in } \\
\text { altering fertility outcomes }\end{array}$ \\
Low & 1.845 & $\begin{array}{l}\text { Fertility levels are in-between that of median and lowest scenarios } \\
\text { Assumes rapid and effective integration efforts, although moderate dif- } \\
\text { ferences are apparent }\end{array}$ \\
& Fertility levels conform to that of natives \\
Lowest & Severe disruptions and/or full integration
\end{tabular}


- That net-Syrian migration returns to pre-crisis levels following the first projection (year $t+5$ ). Due to nature of Syrian migration, it is assumed that the extreme inflows observed from 2011 to 2015 will not persist.

- That the Syrian migrant population remain in Germany for the entirety of the projection period. This is not unlikely. As shown by Backman et al. (2019) analysing the educational and employment trajectories of refugee migrants in Sweden between 1991 and 2013, less than 5\% of refugees leave the country during this 22-year period, and it is very unlikely that many will leave as nearly $90 \%$ of these migrants have stable employment conditions and they are presumably settled in the country.

\subsection{Bayesian probabilistic projections}

A Bayesian probabilistic projection model was used to forecast future fertility and overall population levels from 2020 to 2100. Cohort component projections are produced assuming constant fertility, mortality and migration outcomes, but this assumption is highly unlikely in the long term. Bayesian models account for fluctuation and expected trends in fertility and mortality, providing a more realistic projection of future population. We implemented Bayesian projections by using recently developed R packages by Ševciková et al. (2014).

Generating country-level Bayesian projections involves three stages in which fertility, mortality and population trajectories are projected separately (Ševciková et al. 2014). Firstly, country-specific period fertility parameters are estimated. To this end, one of two Bayesian hierarchical models (BHM) can be applied depending on whether a country displays pre- or post-transitional demographic traits (Alkema et al. 2011). Future fertility trajectories are then modelled using a Markov Chain Monte Carlo (MCMC) method. These trajectories are simulated multiple times, adhering to the defined parameters. This is repeated for each country and considers historic fertility data, if available, to project a posterior distribution of period fertility. Secondly, a similar process is applied to model life expectancy trajectories. Country-specific parameters are defined using a BHM (see Raftery et al. 2013) and MCMC is used to model expected increases in life expectancy (Oeppen and Vaupel 2002). The method considers gender disparities in health outcomes through modelling a gap between female and male life expectancies (Raftery et al. 2014). Finally, overall population trajectories are generated through applying the cohort component method, in which the previously simulated fertility and mortality components are considered. Migration is the only constituent that is not assessed probabilistically and input data are derived from the UN World Population Prospects revisions. UN's expectations involve positive net-migration in developed countries to gradually diminish, with neutral migration for all cohorts expected by 2050. A decreasing migration function is therefore applied to our German Bayesian population projections. A custom fertility dataset is applied to assess the likely impact of TFR differentials, under the different scenarios, on future demographic outcomes. 
We also examine geographical variations in the fertility outcomes resulting from Syrian migration. We estimate the net total fertility effect of Syrian migrants across the 16 states, or Länder, of Germany. Cohort component projections are produced until 2020, applying the same underlying assumptions. Survivorship probabilities were assumed to remain the same as that for Germany, in addition to zero net-migration between regions. Birth and population data were acquired from the regional statistics data portal (GENESIS). From this, ASFR's were calculated using equation one, see above. To estimate Syrian migrant count, distribution quotas were acquired from the German Federal Office for Migration and Refugees website (www.bamf. de). These were applied by simply dividing the total national Syrian migrant count for each age and sex cohort by the appropriate distribution quota. Syrian migrant demographic distributions were assumed to remain constant for each state, varying only by allocated distribution as per the quota.

\section{Results}

\subsection{Demographic comparisons of native and Syrian migrant populations}

Considerable differences between the German and migrant populations are likely to alter the structure of the national population and local aggregate fertility rates. In 2015, 326,872 migrants from Syria arrived in Germany, constituting the largest group of immigrants moving to Germany and comprising $15.3 \%$ of all arrivals (BAMF 2015). Compared to the German population, Table 3, however, reveals that the size of the Syrian migrant population is small, male dominated and considerably younger. The male, 0-14 aged and 15-49 aged populations represent just under $70 \%$, over $40 \%$ and $49 \%$ of the migrant population, respectively. These percentages contrast with the established pattern of population ageing in Germany, but also reflect the fact that a considerable proportion of migrants are children or productive ages, with a potential to mitigate a local trend of population decline.

Figure 1 illustrates the differences in age structure between the native and Syrian migrant population in Germany. The structure of the native population is typical of a post-transitional society, with increasing shares of people in old age groups, and resulting from sustained low fertility and improved mortality outcomes. The population structure of Syrian migrants resembles that of an early stage transitioning society, with considerable populations at younger ages as the predominant feature. The relatively small middle-aged and elderly population is not entirely associated with high mortality at such ages (see Kirk 1996), but reflects differences in the probability to migrate over the life course, in particular low mobility levels at older ages.

Table 4 provides an insight into the immediate demographic effects of Syrian migration into Germany through examining changes in the demographic composition of cohorts as a result of Syrian influx. It reveals that, despite considerable differences in age structure, the net-effect of the young Syrian migration influx on the German population structure has so far been modest. The greatest change is projected to be in the male $0-4$ cohort with an increase of 0.75 people per 1000 , although on the whole a general 'youthening' effect is evident for both genders. 


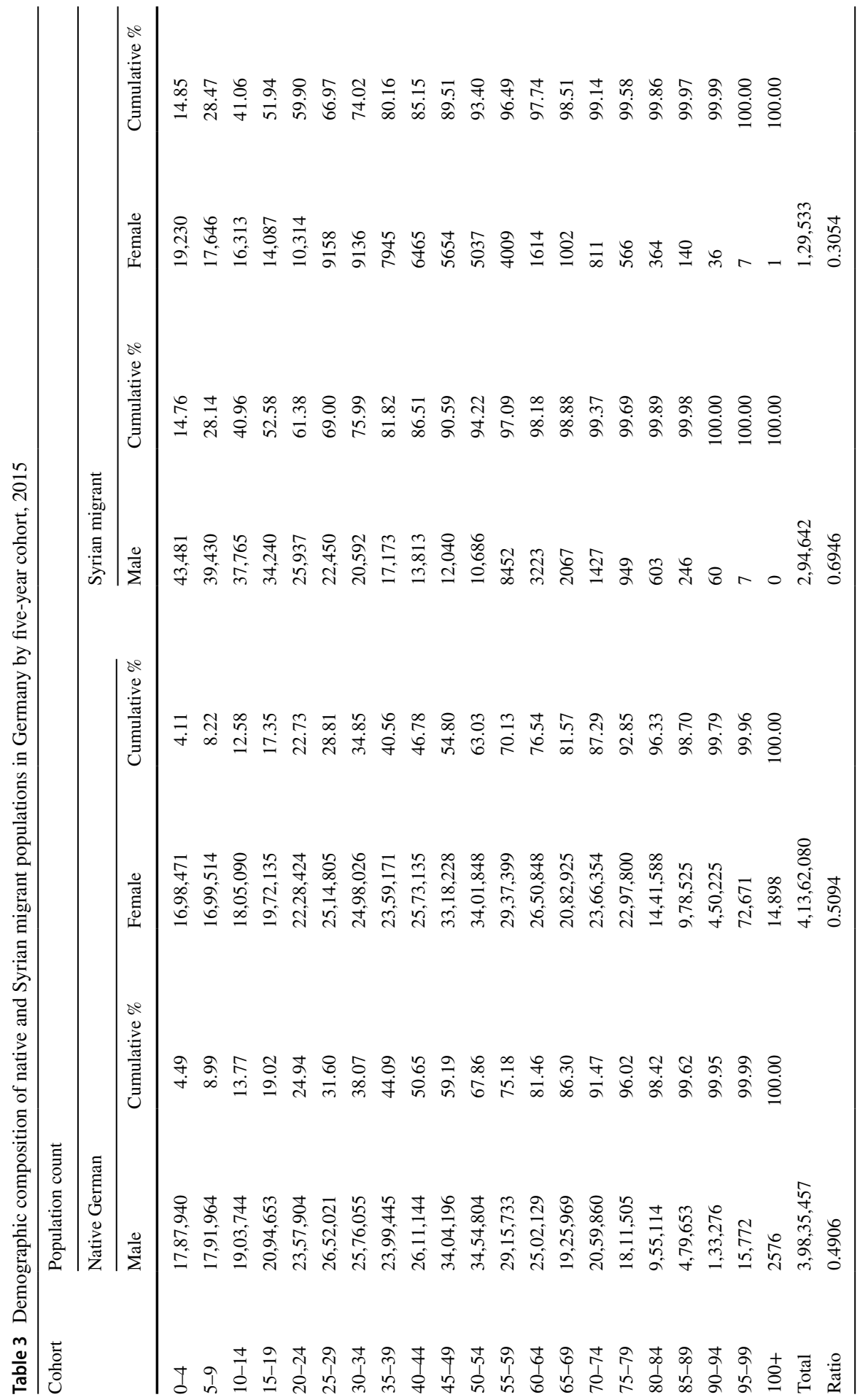




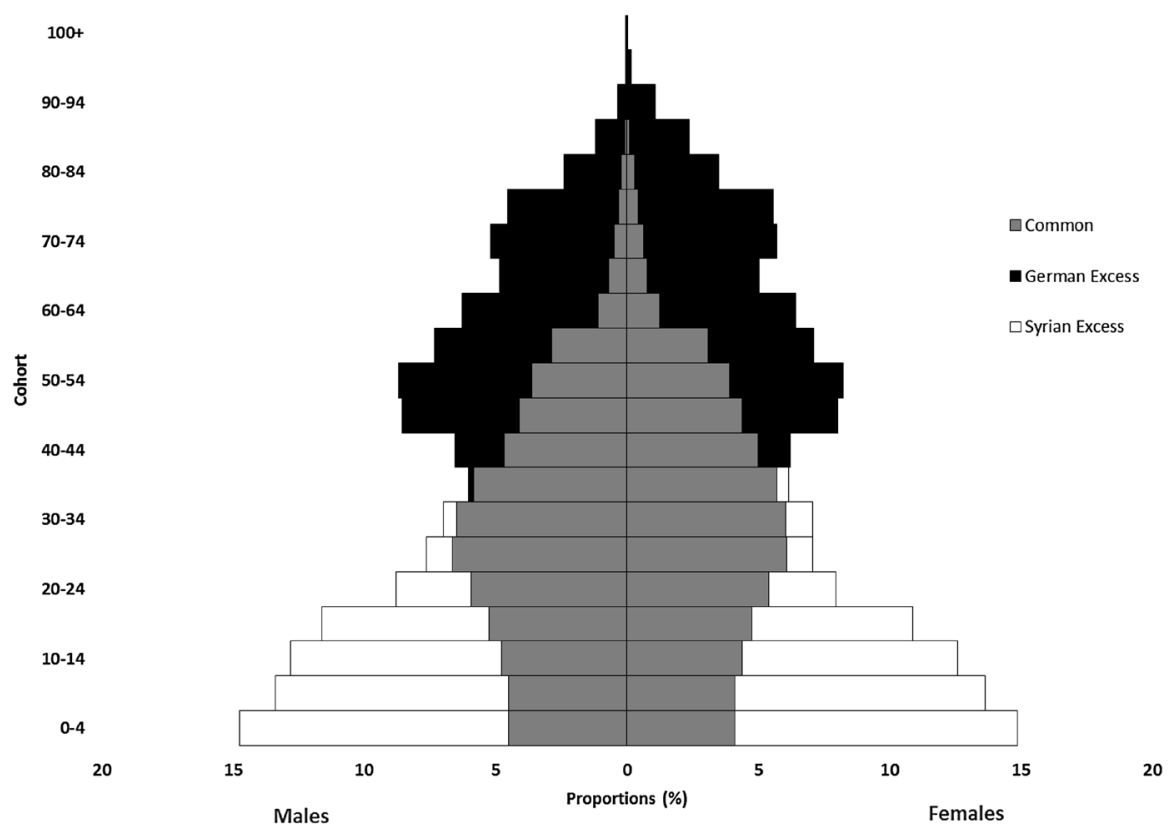

Fig. 1 Population structure of native German and Syrian migrant populations, 2015

\subsection{Cohort component projections}

In this paper, the key conceptual premise centres on the potential of migration influxes to raise fertility rates. To analyse the Syrian migration influx on the German population, as outlined in Sect. 2.1, population projections were produced. Table 5 shows the results of five different population scenarios from a cohort component model. Due to the relatively small Syrian migrant population in Germany, considerable differences between potential Syrian migrant fertility scenarios produce modest increases in aggregate fertility rates. Under the median scenario, Syrian migrants exhibit a TFR of 2.26 children per women, resulting in an aggregate increase of just 0.0039 . As Syrian migrant fertility decreases under different scenarios, a proportional decrease in period fertility contributions from Syrian migration can be observed, ranging from 0 to 0.0077 .

Figure 2 displays the trajectories of population growth under each of the five fertility scenarios, revealing remarkably similar trends (Fig. 2). These trajectories are characterised by an initial phase of growth, resulting from high migration influxes and associated birth increases, followed by intense decline. Increases are projected up to 2030, capturing the temporary recuperation of demographic momentum, which in turn diminishes as reproductive cohorts decrease in size. This period of population momentum is succeeded by rapid depopulation a result of a demographic deficit, even under the assumption of constant non-Syrian immigration. The ultimate effect of recent migration influxes into Germany appears as a temporary fix for depopulation, rather than a permanent solution. By the end of the projection period, 
Table 4 Projected impact of Syrian migrant influx on the demographic composition of Germany, 2015

\begin{tabular}{|c|c|c|c|c|c|c|}
\hline \multirow[t]{3}{*}{ Cohort } & \multicolumn{6}{|c|}{ Population proportions (per 1000) } \\
\hline & \multicolumn{3}{|l|}{ Male } & \multicolumn{3}{|l|}{ Female } \\
\hline & Pre-Mig & Post-Mig & Change & Pre-Mig & Post-Mig & Change \\
\hline $0-4$ & 44.88 & 45.64 & 0.75 & 41.06 & 41.40 & 0.34 \\
\hline $5-9$ & 44.98 & 45.64 & 0.65 & 41.09 & 41.39 & 0.30 \\
\hline $10-14$ & 47.79 & 48.38 & 0.59 & 43.64 & 43.90 & 0.26 \\
\hline $15-19$ & 52.58 & 53.05 & 0.47 & 47.68 & 47.87 & 0.19 \\
\hline $20-24$ & 59.19 & 59.40 & 0.21 & 53.88 & 53.96 & 0.08 \\
\hline $25-29$ & 66.57 & 66.65 & 0.07 & 60.80 & 60.83 & 0.03 \\
\hline $30-34$ & 64.67 & 64.71 & 0.04 & 60.39 & 60.43 & 0.03 \\
\hline $35-39$ & 60.23 & 60.22 & -0.01 & 57.04 & 57.05 & 0.01 \\
\hline $40-44$ & 65.55 & 65.41 & -0.14 & 62.21 & 62.17 & -0.04 \\
\hline $45-49$ & 85.46 & 85.13 & -0.33 & 80.22 & 80.11 & -0.11 \\
\hline $50-54$ & 86.73 & 86.36 & -0.37 & 82.25 & 82.11 & -0.14 \\
\hline $55-59$ & 73.19 & 72.87 & -0.33 & 71.02 & 70.89 & -0.13 \\
\hline $60-64$ & 62.81 & 62.43 & -0.38 & 64.09 & 63.93 & -0.16 \\
\hline $65-69$ & 48.35 & 48.04 & -0.30 & 50.36 & 50.23 & -0.13 \\
\hline $70-74$ & 51.71 & 51.37 & -0.34 & 57.21 & 57.05 & -0.16 \\
\hline $75-79$ & 45.47 & 45.16 & -0.31 & 55.55 & 55.39 & -0.16 \\
\hline $80-84$ & 23.98 & 23.82 & -0.16 & 34.85 & 34.75 & -0.10 \\
\hline $85-89$ & 12.04 & 11.96 & -0.08 & 23.66 & 23.59 & -0.07 \\
\hline $90-94$ & 3.35 & 3.32 & -0.02 & 10.88 & 10.85 & -0.03 \\
\hline 95-99 & 0.40 & 0.39 & 0.00 & 1.76 & 1.75 & -0.01 \\
\hline $100+$ & 0.06 & 0.06 & 0.00 & 0.36 & 0.36 & 0.00 \\
\hline
\end{tabular}

Pre-Mig denotes the demographic composition of Germany prior to Syrian migration

Post-Mig denotes the demographic composition of Germany after Syrian migration

Table 5 Results of cohort component projection models for each Syrian migrant fertility scenario including pre-projection 2015 TFR and population count

\begin{tabular}{|c|c|c|c|c|c|c|c|}
\hline & & & \multicolumn{5}{|l|}{ Scenario } \\
\hline & & & Highest & High & Median & Low & Lowest \\
\hline \multirow[t]{3}{*}{ TFR } & & 2015 & 1.4270 & 1.4270 & 1.4270 & 1.4270 & 1.4270 \\
\hline & 2020-2050 & & 1.4347 & 1.4328 & 1.4309 & 1.4289 & 1.4270 \\
\hline & Syrian Contributi & ion & 0.0077 & 0.0058 & 0.0039 & 0.0019 & 0 \\
\hline \multirow{5}{*}{$\begin{array}{l}\text { Population } \\
\text { (Thousands) }\end{array}$} & 2015 & & 81,198 & 81,198 & 81,198 & 81,198 & 81,198 \\
\hline & & 2020 & 82,800 & 82,799 & 82,799 & 82,799 & 82,799 \\
\hline & & 2030 & 83,745 & 83,735 & 83,727 & 83,719 & 83,710 \\
\hline & & 2040 & 83,394 & 83,376 & 83,359 & 83,343 & 83,326 \\
\hline & & 2050 & 81,988 & 81,960 & 81,934 & 81,908 & 81,883 \\
\hline
\end{tabular}




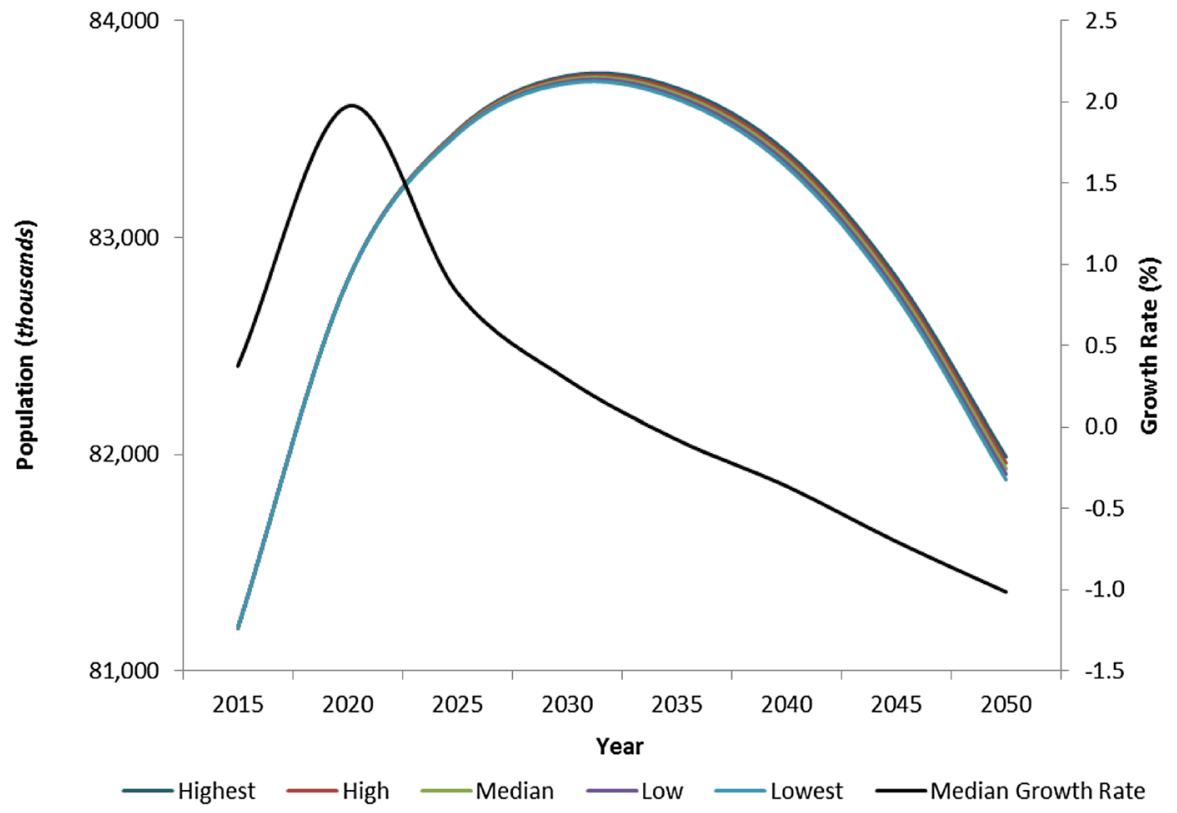

Fig. 2 Germany population projections for each scenario, 2015-2050

Table 6 Aggregate 5-year age-specific fertility rates (ASFR) under each scenario (2020-2050) including pre-projection year (2015)

\begin{tabular}{lllllll}
\hline Cohort & Germany 2015 & \multicolumn{2}{l}{ Scenario } & & \\
\cline { 3 - 7 } & & Highest & High & Median & Low & Lowest \\
\hline $15-19$ & 0.0403 & 0.0417 & 0.0414 & 0.0410 & 0.0407 & 0.0403 \\
$20-24$ & 0.1835 & 0.1862 & 0.1855 & 0.1848 & 0.1842 & 0.1835 \\
$25-29$ & 0.4023 & 0.4040 & 0.4035 & 0.4031 & 0.4027 & 0.4023 \\
$30-34$ & 0.4875 & 0.4883 & 0.4881 & 0.4879 & 0.4877 & 0.4875 \\
$35-39$ & 0.2641 & 0.2648 & 0.2646 & 0.2644 & 0.2642 & 0.2641 \\
$40-44$ & 0.0474 & 0.0477 & 0.0476 & 0.0475 & 0.0474 & 0.0474 \\
$45-49$ & 0.0020 & 0.0021 & 0.0021 & 0.0021 & 0.0020 & 0.0020 \\
\hline
\end{tabular}

the population of Germany is projected to increase, but with clear signs of a declining trajectory.

Whilst the effect of Syrian immigration on total population numbers is small, considerable differences are estimated across age-specific fertility rates (ASFR, see Table 6). Younger cohorts are projected to register the largest fertility increases, particularly women aged 25-29 and 30-34. In contrast, older cohorts are forecasted to experience less significant rises. Under the median scenario, the ASFR for the 20-24 cohort is expected to increase by 0.0014 whereas increases of 0.0002 are 
expected for the $40-44$ cohort. These equate to an additional 1.38 and 0.18 births per thousand of the population, respectively.

\subsection{Bayesian projections}

Unlike cohort component projections, Bayesian projections are probabilistic enabling the assessment of the likelihood of realisation of a particular trajectory. Bayesian projections are not restricted by unrealistic demographic assumptions that are tied to cohort component models (e.g. constant fertility or morality rates). Figure 3 illustrates a Bayesian TFR projection under our median migrant fertility scenario. The median trend shows a consistent TFR increase throughout the entire projection period. There is an $80 \%$ probability (red dashed lines) that TFR will be greater in 2100 than at present. However, reductions are possible, as indicated by the wide 95\% confidence bounds (red dotted lines). It is extremely unlikely that TFR will reach replacement level by the end of this century, with the median simulation predicting fertility to stabilise at around 1.8 .

The results of the Bayesian simulations show a consistent improvement in TFR for each scenario (Table 7), implying that Syrian migration will have a significant

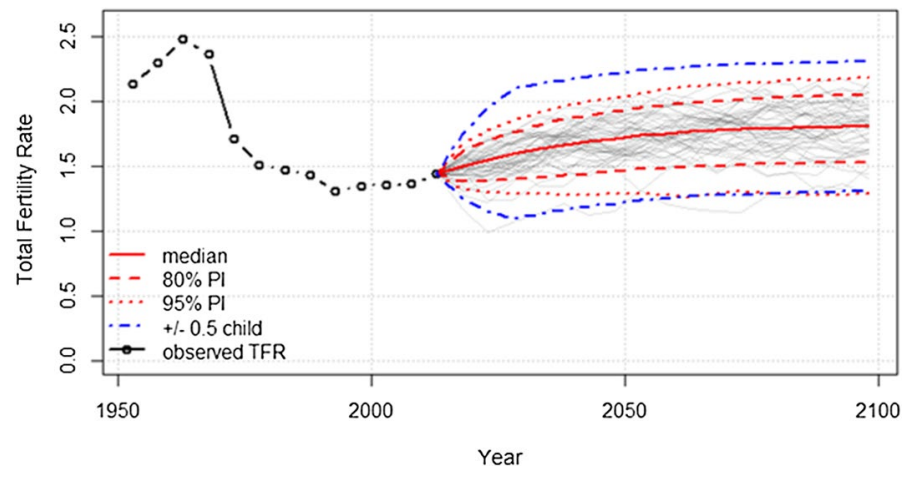

Fig. 3 Median scenario Bayesian total fertility rate projection until 2100

Table 7 Median total fertility rate and population projections from Bayesian models

\begin{tabular}{cllll}
\hline \multirow{5}{*}{ TFR } & & Scenario & \\
\cline { 3 - 5 } & & Highest & Median & Lowest \\
\hline & $2020-2025$ & 1.547 & 1.544 & 1.538 \\
& $2045-2050$ & 1.711 & 1.703 & 1.697 \\
& $2070-2075$ & 1.780 & 1.777 & 1.770 \\
Population & $2095-2100$ & 1.810 & 1.806 & 1.813 \\
(thousands) & 2050 & $80,688.55$ & $80,688.55$ & $80,688.55$ \\
& 2100 & $74,721.28$ & $74,645.24$ & $74,653.57$ \\
& & $66,786.81$ & $66,531.53$ & $66,719.39$ \\
\hline
\end{tabular}


positive influence on German fertility. However, Syrian migration is assumed to cease following 2020 (as according to assumptions outlined in Sect. 3.1); therefore, further increases in TFR, as demonstrated in Table 7, are not caused by Syrian migration. Rather, the scenario-dependent net-effect on fertility is represented only by the initial differences in TFR. The mechanism of Bayesian simulations (i.e. a random walk with drift model) facilitates variations between projection scenarios. These may not follow a specific hierarchical pattern, resulting in the lowest fertility scenario with a larger projected TFR than the highest and median variant as in Table 7. However, the most common structure is a consistent hierarchical pattern. In considering all model results, TFR is estimated to increase to around 1.81 by 2100 and population to decline to around 66.7 million.

Figure 4 illustrates the projected trajectory of population change under the median scenario, revealing a very likely trend of population decline. Whilst considerable uncertainty exists, the result shows that there is an $80 \%$ chance the German population will decline very rapidly after 2030 , with median estimates projecting a population of 74.6 million by 2050. As a result of the declining netmigration function employed in Bayesian models, this depopulation trend can be attributed to the combined impact of a severe birth deficit and an asymptotic influence of positive net-migration. However, the upper $95 \%$ confidence bound for our population projections suggests that population growth may be possible from around 2075, contrasting with the lower bound which indicates a near linear decline.

Bayesian models enable examination of likely future population structures. Figure 5 displays our Bayesian projections by five-year age bands, revealing significant alterations in the demographic composition of the German population. First, an overall ageing of the population is projected and seems highly probable, with elderly cohorts $(60+)$ displaying increases in proportion for males and females and marked gender disparity in level of these increases. Secondly, the 45-59 cohort is projected to undergo the greatest change, shrinking by over $10 \%$. Youth cohorts $(0-4,5-9)$ display an increase under the median scenario. However, uncertainty is large due to

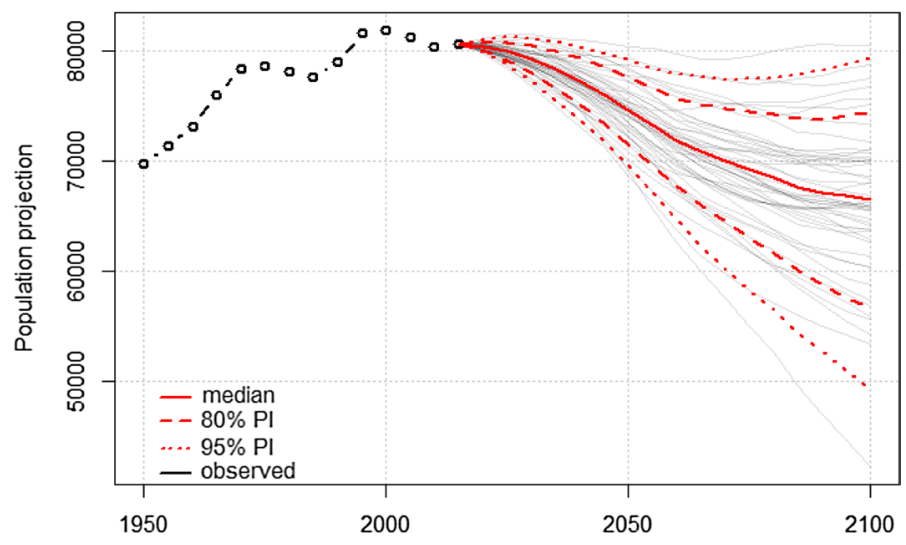

Fig. 4 Bayesian population projection, Median scenario until 2100 


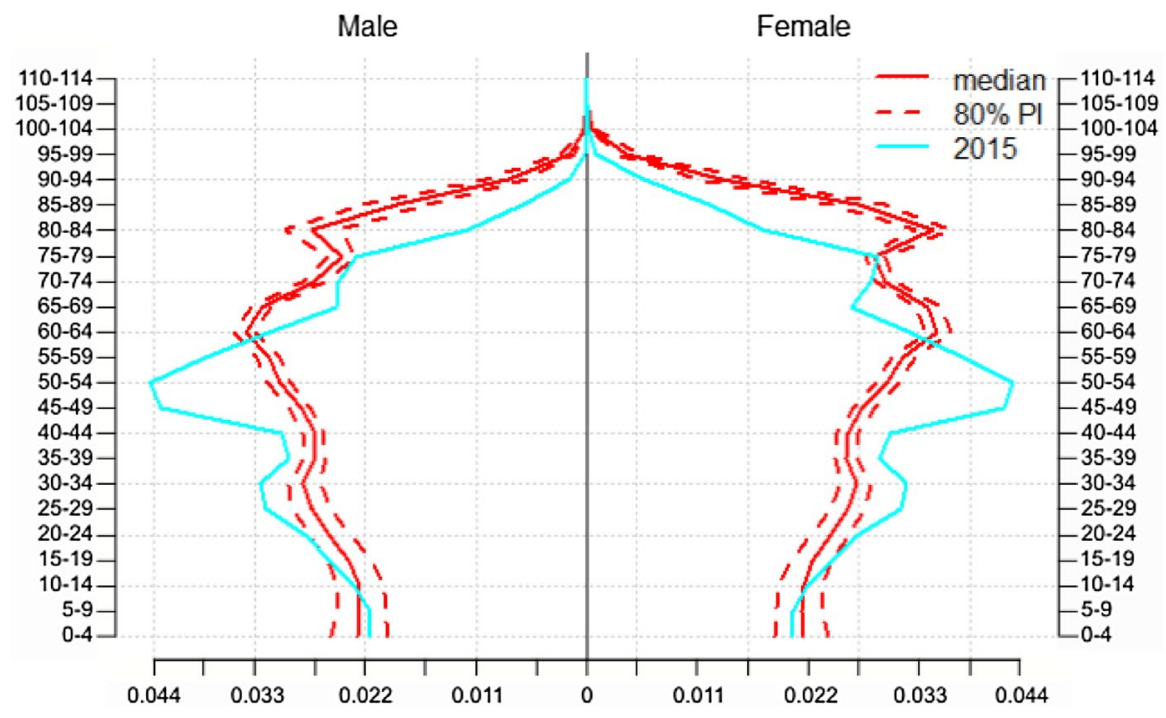

Fig. 5 Population structure of Germany 2050, constructed using Bayesian population projection Median scenario results

fertility uncertainties (Fig. 3) - as indicated by the $80 \%$ confidence bounds, pointing to potential population decline. Finally, all fertile cohorts (15-49) are projected to decline under statistical scenario, likely reflecting the assumed decrease in positive migration and current low-fertility rates. However, this will not necessarily translate to a decrease in the actual count of fertile cohort population.

\subsection{Regional cohort component analysis}

The influx of Syrian migrants is likely to generate differentiated impacts on local population structures. Quotas are used to relocate Syrian migrants across German states through a system named EASY. Refugees are assigned to a particular state based on the local population count and tax revenue. Thus, more populous states, such as Bayern and Nordrhein-Westfalen, receive larger shares of Syrian migrants than less-populous regions, such as Bremen or Saarland (Table 8).

Figure 6a shows the spatial distribution of Syrian migrants in Germany. A clear distinction emerges between former Eastern and Western German states. Former Soviet-occupied states, including Brandenburg, Freistaat Sachsen, MecklenburgWest Pomerania, Sachsen-Anhalt and Thüringen, tend to display lower migrant populations than Western states, with the former receiving just $15.73 \%$ of all Syrian migrants.

In addition to examining the relative importance of the Syrian population across states, it is also important to identify differences in fertility patterns in order to assess the impact of Syrian influxes on local population structures. Figure $6 \mathrm{~b}$ displays considerable spatial variation in pre-migration period TFR across German 
Table 8 Demographic impact of Syrian migration by German state, 2020

\begin{tabular}{|c|c|c|c|c|c|c|c|}
\hline \multirow[t]{2}{*}{ Region } & \multicolumn{2}{|c|}{ Syrian Migrant } & \multicolumn{5}{|l|}{ TFR } \\
\hline & $\begin{array}{l}\text { Distribu- } \\
\text { tion quota } \\
(\%)\end{array}$ & Population & 2015 & Differential & 2020 & Contribution & Change (\%) \\
\hline Baden-Württemberg & 12.865 & 54,568 & 1.493 & 0.771 & 1.497 & $0.00,352$ & 0.236 \\
\hline Bayern & 15.519 & 65,827 & 1.476 & 0.788 & 1.480 & 0.00373 & 0.252 \\
\hline Berlin & 5.049 & 21,418 & 1.452 & 0.811 & 1.457 & 0.00422 & 0.291 \\
\hline Brandenburg & 3.061 & 12,982 & 1.537 & 0.726 & 1.542 & 0.00424 & 0.276 \\
\hline Bremen & 0.957 & 4059 & 1.503 & 0.760 & 1.507 & 0.00378 & 0.252 \\
\hline Hamburg & 2.530 & 10,730 & 1.446 & 0.818 & 1.450 & 0.00426 & 0.294 \\
\hline Hessen & 7.359 & 31,215 & 1.493 & 0.770 & 1.497 & 0.00359 & 0.241 \\
\hline $\begin{array}{l}\text { Mecklenburg-West } \\
\text { Pomerania }\end{array}$ & 2.029 & 8607 & 1.557 & 0.706 & 1.561 & 0.00382 & 0.245 \\
\hline Niedersachsen & 9.321 & 39,538 & 1.507 & 0.757 & 1.510 & 0.00347 & 0.230 \\
\hline $\begin{array}{l}\text { Nordrhein-West- } \\
\text { falen }\end{array}$ & 21.210 & 89,968 & 1.505 & 0.759 & 1.508 & 0.00343 & 0.228 \\
\hline Rheinland-Pfalz & 4.837 & 20,518 & 1.503 & 0.761 & 1.507 & 0.00354 & 0.235 \\
\hline Saarland & 1.222 & 5182 & 1.374 & 0.889 & 1.379 & 0.00434 & 0.316 \\
\hline Sachsen-Anhalt & 2.831 & 12,007 & 1.550 & 0.714 & 1.554 & 0.00396 & 0.255 \\
\hline Freistaat Sachsen & 5.084 & 21,564 & 1.598 & 0.666 & 1.601 & 0.00388 & 0.243 \\
\hline Schleswig-Holstein & 3.403 & 14,436 & 1.501 & 0.762 & 1.505 & 0.00364 & 0.242 \\
\hline Thüringen & 2.725 & 11,557 & 1.571 & 0.693 & 1.575 & 0.00392 & 0.250 \\
\hline
\end{tabular}

states in 2015. Former East Germany display higher fertility rates than West German states, reflecting a major contemporary change in the fertility trajectories of East and West Germany. The total fertility of East Germany declined and remained below that of the West for almost 20 years following reunification, but it has recently overtaken (in 2008) that in the West for the first time as a result of a lower proportion of childlessness and recuperation of higher order births (Goldstein and Kreyenfeld 2011).

Figure $7 \mathrm{a}, \mathrm{b}$ reports our population projection results. Figure $7 \mathrm{a}$ shows the projected TFR for 2020. Figure 7b illustrates the spatial variation of TFR contributions from Syrian migrants across the German states. This was calculated by subtracting the pre-migration 2015 TFR from the 2020 TFR projections. As per our assumptions (Sect. 3.1), the only source of fertility change in our cohort component models is the addition of Syrian migrants. The results reveal that although Western states have received a greater number of Syrian migrants, Eastern states are projected to experience the largest increases in total fertility, leading to a TFR of between 1.55 and 1.6 in Mecklenburg-West Pomerania, Thuringen and Freistaat Sachsen. The results also reveal that whilst Bayern and Baden-Wurttemberg have received the largest receivers of Syrian migrants, their TFRs are projected to remain low. Additionally, whilst the total fertility is projected to remain very low in small states, such as Berlin, Hamburg and Saarland, they are expected to record the greatest increases in fertility due to the influx of Syrian migrants. 

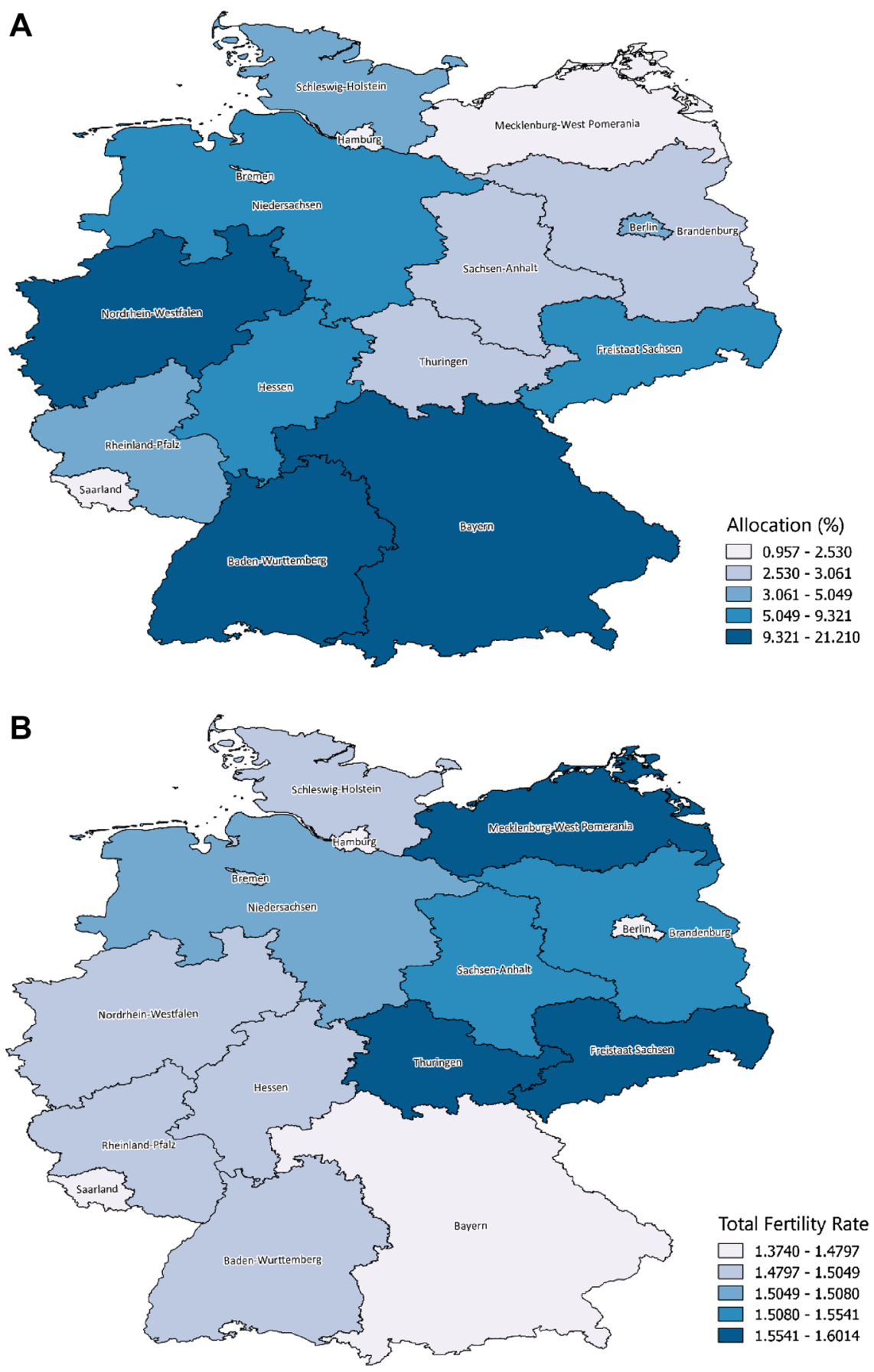

Fig. 6 Allocation of Syrian migrants across German states (a), state-specific Total Fertility Rate (TFR) pre-Syrian migration, 2015 (b) 

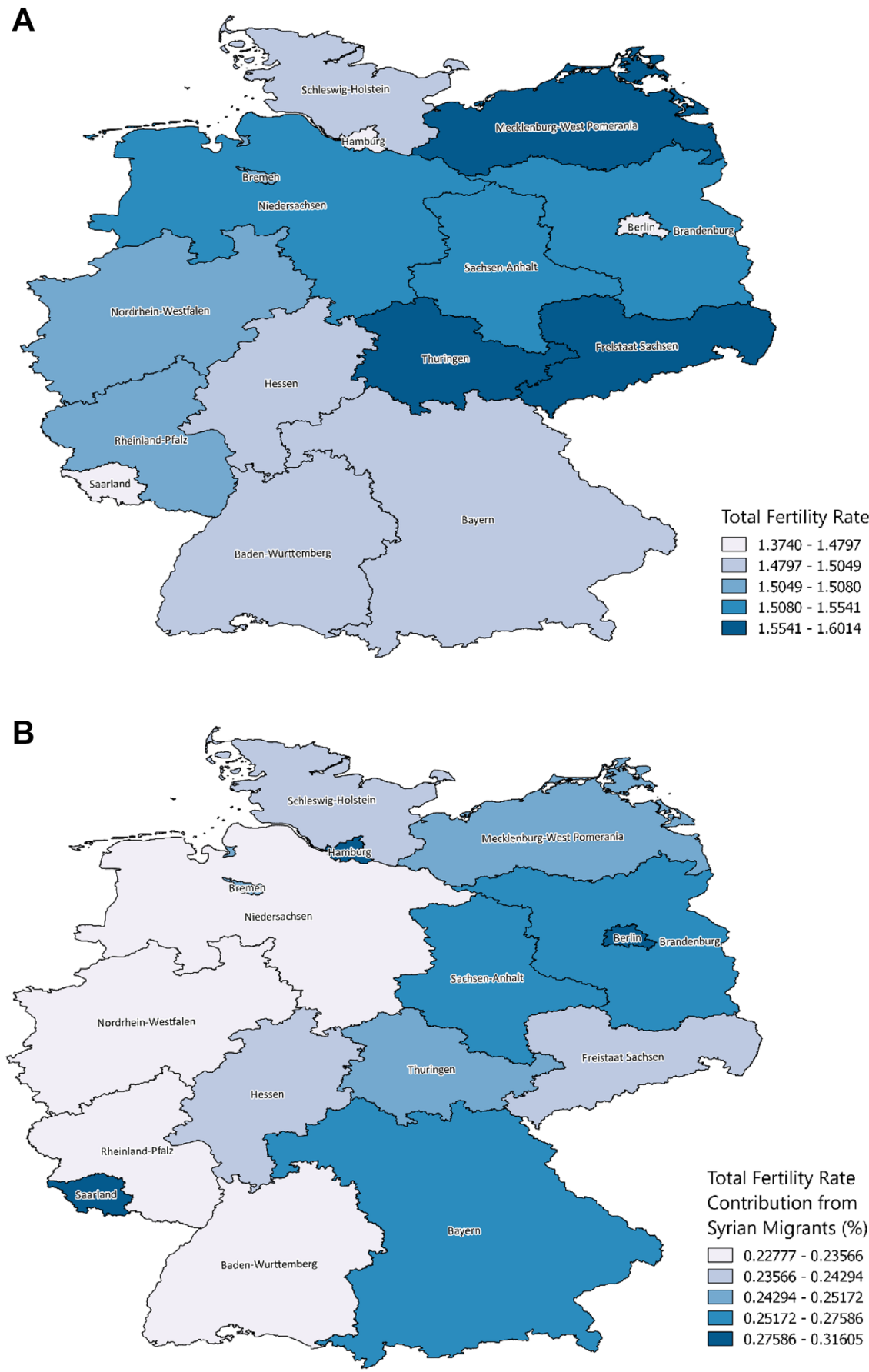

Fig. 7 Projected post-Syrian migration TFR, 2020 (a). Fertility contributions from Syrian migrants for each German state, 2020 (b) 


\section{Discussion}

Set to undergo population decline, positive net-migration in Germany is crucial to limiting the negative consequences of this process (Coleman and Rowthorn 2011). Over the 2011-15 period, net-migration in Germany accounted for $3.4 \%$ of the national population. In its absence, the population would have declined by over 1.16 million (1.5\%). Supported by our cohort component analysis, depopulation is likely to occur in Germany even if current levels of non-Syrian migration are maintained. This scenario can, however, be altered by future changes in local fertility and mortality outcomes and migrant fertility behaviour. Our probabilistic forecasts assume a steadily decreasing migration function over the projection period, and so demonstrate likely declines as a consequence, even when fertility converges towards replacement level. Migration is, however, very volatile and difficult to predict (Coleman 2008).

Syrian migrant influxes are likely to have a positive impact on the German TFR. Under all migrant fertility scenarios, an increase in completed births is guaranteed, even in the lowest variant. However, on the whole, increases to TFR are expected to be modest. Assuming the sustention of pre-migration disparities in fertility outcomes between native and Syrian migrant populations (highest scenario), total fertility would increase by 0.0077 births per woman. Even under these optimistic conditions, German total fertility rate would remain below the 'safety zone' bound of 1.5 children per woman (McDonald 2006) and should still be considered as very low.

Ultimately the extent of fertility improvements is dependent on the prevalence of fertility inhibiting factors during the various stages of migration. Although the probability of which scenario will be realised is not quantitatively assessed in this study, it is likely that migrant fertility will lie somewhere in between the extreme scenarios reported. Immigrants in Germany are identified to have considerably higher levels of total fertility than the native German population (Milewski 2010) but a lower TFR than their respective countries of origin (Mammey and Schwarz 2002). This means that fertility increases under the highest scenario are likely to overestimate the impact of the Syrian migrant population in Germany as their pre-migration fertility behaviour was assumed for the projections. However, because not all Syrian migrants are included in the analysis, actual increases to total fertility may, on the other hand, have been underestimated. Thus, the projected migrant fertility outcomes should be interpreted cautiously.

A major cause underpinning the modest changes in TFR is the small size of fertile migrant cohorts. As reported by Sobotka (2008), improvements to total fertility of between 0.05 and 0.1 births per woman are typically observed following considerable migration flows. In Germany, the fertile female Syrian migrant population represents just $0.36 \%$ of the total cohort. This is considerably smaller than in Norway, for example, where the fertile immigrant population accounts for $6.71 \%$ (Østby 2002). In the light of the relative size of the cohort of Syrian migrants in Germany, reported increases in period fertility seem considerable and should not be disregarded on the basis of their seemingly small contribution to aggregate period fertility. 
Across states, differentials in TFR between the native and Syrian migrant populations are not the only driver of projected fertility outcomes. Our results reveal a complex relationship between these patterns and states' Syrian migrant intake. Migration intake by state is determined by population size, and thus projected fertility outcomes are also influenced by the relative ratio of the migrant to native population. Thus, for instance, whilst fertility is projected to record relatively large increases in Eastern states and small states, such as Berlin and Bremen, mainly as result of receiving a relatively large migration influx relative to the native population, forecasted rises in TFR in low-fertility states such as Bayern and Saarland are primarily attributed to fertility differentials between the native and migrant populations.

Our projections also reveal three potential sources of fertility increase to promote future population growth. First, our Bayesian estimates project a gradual convergence of German total fertility towards replacement level during the course of the present century, signalling the end to an era of extreme low fertility. Although uncertainty exists within the literature regarding the extent of expected recuperations (Sobotka 2017), our Bayesian simulations indicate that replacement fertility is not essential for population stabilisation. Rather, a combination of slightly increased fertility outcomes and continued life expectancy improvements will suffice to reduce the rate of decline and produce a stable population by the end of the century, albeit at a considerably reduced size. This scenario was generated assuming neutral net-migration, indicating potential for population growth if present positive migration and subsequent fertility increases are sustained.

Second, youth cohorts (0-4 and 5-9) are projected to increase as a result of migrant influxes and improved fertility outcomes. However, cohorts from age 20 to 59 are expected to decline with a consequential rise of older cohorts (i.e. $60+)$, resulting in accelerated population ageing. Whilst increases in youth cohorts does not represent a reversal of population ageing, it will alleviate its effects. Third, projected increase in fertility rates for young cohorts as a result of the Syrian migrant influx could induce future improvements in fertility outcomes. Direct increases to completed births can be realised from these young cohorts. A reduction in the mean age of mothers at childbirth could also alleviate the prevalence of fertility inhibiting factors associated with fertility postponement arising from population which decreases parity progression (Kohler and Ortega 2002). However, whether the migrant population will undergo a similar postponement transition will be largely dependent on the extent of integration into the German society.

The impact of Syrian influxes on alleviating an ageing population seems small, but the vast majority of migrants in Germany $(85 \%)$ come from other countries. Thus, increases in aggregate fertility are highly likely, even if fertility traits are more closely aligned to those of German natives than to those of Syrian migrants. The proportion of births from migrant women has increased by $4.2 \%$ since reunification (DESTATIS 2017a, b, c). Future research should explore the period fertility contributions from non-Syrian migrants. Additionally, fertility outcomes of second-generation migrants, i.e. migrants' descendants, could provide additional increases to aggregate fertility rates as an indirect 
result of migration inflows. If greater fertility is found for second-generational Syrian migrants, as evidenced by some migrant groups in Europe (Kulu et al. 2017), increases to fertility rate could be expected-although these are likely to be less than that of first-generation migrants, if generational convergence of period and parity-specific fertility outcomes are observed similar to Turkish immigrants (Milewski 2010). Overall contributions from migrants therefore may not necessarily end with the completion of first-generation births, and actual increases may be higher than reported.

Taken together, our results reveal that overall increases to fertility as a result of recent Syrian migration are inadequate to inhibit the looming prospect of depopulation in Germany. In order to restore fertility levels to replacement and reverse population decline, aggregate TFR increases of around 0.65 are required. Syrian migration constitutes less than a tenth of this. Existing empirical studies indicate that improvements in this magnitude as a consequence of migration would be unprecedented and therefore unreasonable to expect such level from immigration alone (Sobotka 2008; Goldstein et al. 2009).

\section{Conclusions}

The past long-term trajectory of below-replacement fertility in European countries has set an imminent pathway of population decline. This trend of depopulation is anticipated to impose challenges for economic development and social welfare. Yet immigration has been seen as a potential solution to curb population shrinking through increased fertility. This paper produces a set of population scenarios to examine the demographic impact of recent politically driven mass migration from Syria into Germany, a country with a long history of low fertility.

Our projections revealed that, despite its high volume, Syrian migration into Germany would be insufficient to prevent depopulation. Assuming a constant fertility rate, by 2020 German population is expected to decline by 1.18 million. Syrian migrant population only constitutes half the required population influx to prevent short-term decline. Population decline will, however, be averted, at least for a short period, by influxes of migrants (Fig. 2). Positive net-migration has surged in Germany over the past 5 years and is the sole factor responsible for projected shortterm population growth. Considerable continuing immigration inflows will be integral to combatting depopulation. Our projections showed constant net-migration at the current level would not be sufficient to counteract the depopulation in the long term. Thus, increasing fertility emerges as the only feasible solution. Yet, fertility increases as a consequence of Syrian migration would not be enough. Whilst increases to total fertility per migrant were found to be relatively high, in comparison with other similar studies that are based on different population subgroups in different European countries, fertile migrant cohorts are still too small to increase fertility to a necessary level that would curve a trajectory of population decline.

Secondly, our analysis also revealed spatial discrepancies in the impact of Syrian refugee immigration on local fertility rates. Overall period fertility increases were found to be the highest in German states with larger ratios of native 
population to Syrian immigration, involving smaller city-states and ex-East Germany states. Whilst fertility increases in these states were small, with the greatest increase observed in Saarland at just 0.0043 additional births per woman, they are likely to accentuate disparities in total fertility rate between East Germany and West Germany over time.

Thirdly, our Bayesian population projections predicted a modest increase in German total fertility rate by the end of the current century to around 1.8 births per woman. Whilst uncertainty tends to increase with forecast horizon length (Wilson and Rowe 2011; Wilson et al. 2018), our projections are likely to under-estimate fertility increases as net-migration gains through refugee immigration were not considered but are expected to continue. Fertility increases are thus attributable to native women' fertility patterns. Yet this does not imply sufficient fertility rises to combat population decline. Our results showed that projected fertility increases are likely to coincide with rapid population declines and thus Germany is set to experience depopulation in the forthcoming decades. Fertility should thus be actively encouraged by the national government through the introduction of policies and incentives that are supportive of the modern family system.

Additionally, there are a few potential sources of fertility increases in Germany that should be acknowledged. In addition to an expected recuperation of the total fertility rate following the completion of the postponement transition as suggested by Bongaarts and Sobotka (2012), Bayesian estimates project likely increases in youth cohorts by 2050 which should translate into increased completed births. Also, the growing migrant population in Germany is expected to have a momentum effect, lifting the total fertility rate. Although not quantitatively assessed in this study, further increases in the proportion of births from immigrant woman can be expected as a result of recent influxes, which will result in an increased total fertility rate.

Population decline thus appears imminent in Germany as a result of sustained sub-replacement fertility. Substantial increases in net-migration observed over the past 5 years may delay the onset of depopulation for a short period, but this alone is unlikely to curve the projected trajectory of population decline. The impact of Syrian immigration on fertility is likely to be minimal, as migration influxes are inadequate to counter projected natural declines and resulting fertility contributions fall short of required levels. Immigration is, however, a key source of population growth for Germany, with the injection of a relatively youthful migrant population being a major source of immediate and future growth. Population decline has remained largely overlooked in existing scholarship. Yet our evidence indicates that population decline is likely to be an imminent outcome in many developed countries displaying demographic trends similar to Germany. Further efforts are needed to develop appropriate responses and assessment of future population scenarios.

OpenAccess This article is distributed under the terms of the Creative Commons Attribution 4.0 International License (http://creativecommons.org/licenses/by/4.0/), which permits unrestricted use, distribution, and reproduction in any medium, provided you give appropriate credit to the original author(s) and the source, provide a link to the Creative Commons license, and indicate if changes were made. 


\section{References}

Agadjanian V (2018) Interrelationships of forced migration, fertility and reproductive health. In: Demography of refugee and forced migration, Springer, Cham, Gewerbestrasse, Switzerland, pp 113-124

Alho J, Alders M, Cruijsen H, Keilman N, Nikander T, Pham DQ (2006) New forecast: population decline postponed in Europe. Stat J U N Econ Comm Eur 23(1):1-10

Alkema L, Raftery AE, Gerland P, Clark SJ, Pelletier F, Buettner T, Heilig GK (2011) Probabilistic projections of the total fertility rate for all countries. Demography 48(3):815-839

Alkema L, Gerland P, Raftery A, Wilmoth J (2015) The United Nations probabilistic population projections: an introduction to demographic forecasting with uncertainty. Foresight Colch Vt 37:19

Backman M, Lopez E, Rowe F (2019) Career trajectories and outcomes of forced migrants in Sweden: self-employment, employment or persistent inactivity? Small Bus Econ (forthcoming)

BAMF-Bundesamt für Migration und Flüchtlinge (2015) Migrationsbericht 2015 des Bundesamtes für Migration und Flüchtlinge im Auftrag der Bundesregierung. Available: https://www.bamf.de/Share dDocs/Anlagen/DE/Publikationen/Migrationsberichte/migrationsbericht-2015.pdf?_blob=publi cationFile

Beck U, Beck-Gernsheim E (2002) Individualization: Institutionalized individualism and its social and political consequences. Sage, London

Billari FC (2008) Lowest-low fertility in Europe: exploring the causes and finding some surprises. Jpn J Popul 6(1):2-18

Bloom DE (2011) 7 billion and counting. Science 333(6042):562-569

Bloom DE, Sousa-Poza A (2010) Introduction to special issue of the european journal of population: 'economic consequences of low fertility in Europe'. Eur J Popul 26(2):127-139

Bloom DE, Canning D, Fink G (2010) Implications of population ageing for economic growth. Oxf Rev Econ Policy 26(4):583-612

Bongaarts J (1978) A framework for analyzing the proximate determinants of fertility. Popul Dev Rev 4(1):105-132

Bongaarts J, Feeney G (1998) On the quantum and tempo of fertility. Popul Dev Rev 24:271-291

Bongaarts J, Sobotka T (2012) A demographic explanation for the recent rise in European fertility. Popul Dev Rev 38(1):83-120

Booth H (2006) Demographic forecasting: 1980 to 2005 in review. Int J Forecast 22(3):547-581

Bosch X (2000) Spain faces massive decline in population. BMJ 320(7239):891

Coleman D (2006) Immigration and ethnic change in low-fertility countries: a third demographic transition? Popul Dev Rev 32(3):401-446

Coleman D (2008) The demographic effects of international migration in Europe. Oxf Rev Econ Policy 24(3):452-476

Coleman D, Rowthorn R (2011) Who's afraid of population decline? A critical examination of its consequences. Popul Dev Rev 37(s1):217-248

DESTATIS (2017a) Migration between Germany and foreign countries: years 1964-2015. Available: https:/www-genesis.destatis.de/genesis/online/data;jsessionid=CA9EDA642B9238EF5AA56BA83 734CB7E.tomcat_GO_2_2?operation=abruftabelleAbrufen\&selectionname $=12711-0003 \&$ level index $=1 \&$ levelid $=1505387543609 \&$ index $=3$

DESTATIS (2017b) Lebendgeborene nach der Staatsangehörigkeit der Mutter. Available: https://www. destatis.de/DE/ZahlenFakten/GesellschaftStaat/Bevoelkerung/Geburten/Tabellen/LebendgeboreneS taatsangehoerigkeitLaender.html

DESTATIS (2017c) Live births: Germany, years, citizenship, 1960-2015. Available: https://wwwgenesis.destatis.de/genesis/online;jsessionid=01A407A906B5DD070C599D7936E87498.tomca t_GO_2_2?operation $=$ previous\&levelindex $=3 \&$ levelid $=1505466705171 \&$ step $=3$

Dhesi S, Isakjee A, Davies T (2018) Public health in the Calais refugee camp: environment, health and exclusion. Crit Public Health 28(2):140-152

Federal Statistical Office Wiesbaden (2015) Germany's population by 2060. Results of the 13th coordinated population projection. https://www.destatis.de/EN/Publications/Specialized/Population/Popul ation.html

Goldstein S (1973) Interrelations between migration and fertility in Thailand. Demography 10(2):225-241

Goldstein JR, Kreyenfeld M (2011) Has East Germany overtaken West Germany? Recent trends in orderspecific fertility. Popul Dev Rev 37(3):453-472 
Goldstein JR, Sobotka T, Jasilioniene A (2009) The end of "lowest-low" fertility? Popul Dev Rev 35(4):663-699

Haug W, Compton P, Courbage Y (eds) (2002) The demographic characteristics of immigrant populations. Population studies, vol 38. Council of Europe Publishing, Strasbourg

Héran F, Pison G (2007) Two children per woman in France in 2006: are immigrants to blame? Popul Soc 432(March):1-4

Hill K (2004) War, humanitarian crisis, population displacement and fertility: a review of evidence. The National Academies Press, Washington

Keilman N, Pham DQ, Hetland A (2002) Why population forecasts should be probabilistic-illustrated by the case of Norway. Demogr Res 6:409-454

Kirk D (1996) Demographic transition theory. Popul Stud 50(3):361-387

Kohler H-P, Ortega JA (2002) Tempo-adjusted period parity progression measures, fertility postponement and completed cohort fertility. Demogr Res 6(6):91-144

Kohler HP, Billari FC, Ortega JA (2002) The emergence of lowest-low fertility in Europe during the 1990s. Popul Dev Rev 28(4):641-680

Kulu H, Hannemann T, Pailhé A, Neels K, Krapf S, González-Ferrer A, Andersson G (2017) Fertility by birth order among the descendants of immigrants in selected European countries. Popul Dev Rev 43(1):31-60

Lee RD (1998) Probabilistic approaches to population forecasting. Popul Dev Rev 24:156-190

Leslie PH (1945) On the use of matrices in certain population dynamics. Biometrika 33:183-212

Lesthaeghe R, Willems P (1999) Is low fertility a temporary phenomenon in the European Union? Popul Dev Rev 25(2):211-228

Lutz W, O'neill BC, Scherbov S (2003) Europe's population at a turning point. Science 299(5615):1991-1992

Mammey U, Schwarz K (2002) The demographic characteristics of the immigrant population in Germany. Demogr Charact Immigr Popul 38:29-226

McDonald P (2000) Gender equity in theories of fertility transition. Popul Dev Rev 26(3):427-439

McDonald P (2006) Low fertility and the state: the efficacy of policy. Popul Dev Rev 32(3):485-510

Milewski N (2010) Fertility of immigrants: a two-generational approach in Germany. Springer, Berlin

Neyer G, Andersson G (2008) Consequences of family policies on childbearing behavior: effects or artifacts? Popul Dev Rev 34(4):699-724

Oeppen J, Vaupel JW (2002) Broken limits to life expectancy. Science 296(5570):1029-1031

ONS (2015) National Population Projections: 2014-based projections. London, UK

Østby L (2002) The demographic characteristics of immigrant populations in Norway. Reports 2002/22, Oslo: Statistics Norway

Ostrand N (2015) The Syrian refugee crisis: a comparison of responses by Germany, Sweden, the United Kingdom, and the United States. J Migr Hum Sec 3:255

Preston SH, Heuveline P, Guillot M (2001) Demography: measuring and modeling population processes. Blackwell, Malden

Prskawetz A, Buber I, Sobotka T, Engelhardt H (2006) Recent changes in family policies in Austria and Germany: a response to very low fertility. Entre Nous 63:27-29

Quinn E (2016) The refugee and migrant crisis: Europe's challenge. Stud Ir Q Rev 105(419):275-285

Raftery AE, Li N, Ševčíková H, Gerland P, Heilig GK (2012) Bayesian probabilistic population projections for all countries. Proc Natl Acad Sci 109(35):13915-13921

Raftery AE, Chunn JE, Gerland P, Ševčíková H (2013) Bayesian probabilistic projections of life expectancy for all countries. Demography 50:777-801

Raftery AE, Lalic N, Gerland P (2014) Joint probabilistic projection of female and male life expectancy. Demogr Res 30:82-795

Randall S (2004) National research council and committee on population. Fertility of Malian Tamasheq repatriated refugees: the impact of forced migration. National Academies Press, Washigton

Rindfuss RR, Brewster KL (1996) Childrearing and fertility. Popul Dev Rev 22:258-289

Rowe F (2018) Establishing the extent and pace of the contemporary trend of migration decline in Europe. Regions E-Zine. https://regions.regionalstudies.org/ezine/category/research-frontline/?issue $=01$

Ševcıková H, Raftery A, Gerland P (2014) Bayesian probabilistic population projections: do it yourself. Annual meeting of Population Association of America. http://paa2014.princeton.edu/abstr acts/141301 
Sobotka T (2004) Is lowest-low fertility in Europe explained by the postponement of childbearing? Popul Dev Rev 30(2):195-220

Sobotka T (2008) Overview chapter 7: the rising importance of migrants for childbearing in Europe. Demogr Res 19(9):225-248

Sobotka T (2011) Fertility in Central and Eastern Europe after 1989: collapse and gradual recovery. Hist Soc Res 36(2):246-296. https://doi.org/10.12759/hsr.36.2011.2.246-296

Sobotka T (2017) Post-transitional fertility: childbearing postponement and the shift to low and unstable fertility levels. VID Working Paper 1/2017 and Human Fertility Database Research Report 2017001, Vienna: Vienna Institute of Demography

Thomas J, Rowe F, Lin E, (2019) Declining fertility in Taiwan: the deterring impact of housework imbalance. 1/2019 Working Paper, Geographic Data Science Lab, pp 1-35

Tromans N, Jefferies J, Natamba E (2009) Have women born outside the UK driven the rise in UK births since 2001? Popul Trends 136(1):28-42

UN (2001) World population prospects, the 2000 revision. Geneva, Switzerland

UN (2017) World population prospects: the 2017 revision, key findings and advance tables. Working Paper No. ESA/P/WP/248. New York, US

UNDP (2013) Fertility levels and trends as assessed in the 2012 revision of World population prospects. United Nations Publication, New York

UNHCR (2017) Map new asylum applications Europe, April 2011-July 2017. Available: http://data. unhcr.org/syrianrefugees/asylum.php

Van de Kaa DJ (2002) The idea of a second demographic transition in industrialized countries. Policy Seminar of the National Institute of Population and Social Security, Tokyo, Japan, 29 January 2002

Vanella P (2016) The total fertility rate in Germany until 2040: A stochastic principal components projection based on age-specific fertility rates. Hannover Economic Papers (HEP), 579, Leibniz Universität Hannover, Wirtschaftswissenschaftliche Fakultät, Hannover

Wilson T, Rowe F (2011) The forecast accuracy of local government area population projections: a case study of Queensland. Australas J Reg Stud 17(2):204-243

Wilson T, Brokensha H, Rowe F, Simpson L (2018) Insights from the evaluation of past local area population forecasts. Popul Res Policy Rev 37(1):137-155

Wiśniowski A, Smith PW, Bijak J, Raymer J, Forster JJ (2015) Bayesian population forecasting: extending the Lee-Carter method. Demography 52(3):1035-1059

Publisher's Note Springer Nature remains neutral with regard to jurisdictional claims in published maps and institutional affiliations. 